\title{
EL RACIONALISMO MUSULMÁN \\ EN LA EDAD MEDIA
}

\section{MUSLIM RATIONALISM IN THE MIDDLE AGES}

\author{
MigUEL MANZANERA SALAVERT* \\ IES Meléndez Valdés de Villafranca de los Barros
}

RESUMEN: De Avicena es seguramente la expresión más madura del pensamiento racionalista musulmán de la Edad Media Este artículo investiga, desde una perspectiva marxista, cómo se hizo posible ese modo de pensar, cuáles fueron sus raíces históricas y qué organización económica, política y social justificó su aparición. Intenta averiguar también a qué problemas teóricos responde y qué necesidades intelectuales busca resolver. Finalmente esboza una breve exposición de su significado histórico y sus proyecciones hacia el futuro, hoy pasado nuestro.

PAlabras ClaVE: Metafísica, aristotelismo, racionalismo, islam, Edad Media, feudalismo, revolución, historia, teleología, funcionalismo, marxismo, Avicena, al-Farabi, Averroes, Avicebrón, Maimónides.

ABSTRACT: Avicena's Metaphysics is probably the most mature expression of the Muslim rationalist thinking from the Middle Ages. From a Marxist point of view, this essay investigates how this way of thinking came to be, its historical roots and the economic, political and social network that made it possible. It also tries to uncover the theoretical problems it addresses and the intellectual needs tries to solve. Finally, this paper outlines a brief review of its historical significance as well as its future projections, today our past.

KeYwords: Metaphysics, Aristotelianism, rationalism, Islam, Middle Age, feudalism, revolution, history, teleology, functionalism, Marxism, Avicenna, al-Farabi, Averroës, Avicebron, Maimonides.

\footnotetext{
*E-mail: sodepaz.extremadura@gmail.com
} 


\section{Una historia mal contada}

El arabismo es una larga corriente de investigación cultural en nuestro país, si bien no todo lo amplia y profunda que nuestra historia merece. La ignorancia y la hostilidad hacia lo musulmán es una manía española, que proviene de las guerras medievales y de la fundación del Estado español por los Reyes Católicos a finales del siglo XV. Esos acontecimientos condujeron a una limpieza étnica en los primeros siglos de la Edad Moderna en España, con la destrucción de los pueblos peninsulares tal como se habían configurado a lo largo de la Edad Media. Así terminó lo que con toda seguridad fue la cultura más brillante de la Europa medieval, auténtico origen del Renacimiento y de la civilización científica de la modernidad europea.

El 19 de julio de 2011 se conmemoró el XIII Centenario de la batalla de Guadalete, la victoria de las tropas bereberes dirigidas por Tariq ibn Ziyad sobre el ejército visigodo de Don Rodrigo. Ese hecho bélico abrió las puertas de la península ibérica a la revolución musulmana y marca el comienzo de un largo periodo histórico de esplendor cultural en al-Ándalus. Pero dicha batalla de Guadalete no existió, o al menos, no como nos la han contado. El historiador de la Universidad de Sevilla, Emilio González Ferrín, ha insistido en ello durante los últimos años. ${ }^{1}$ Según su tesis, no fue el inicio de una invasión árabe o beréber, sino la consecuencia de una guerra civil interna de los hispano-romanos: los ejércitos que cruzaron el estrecho de Gibraltar habían sido llamados por una facción de los visigodos para combatir al monarca electo por la otra facción. Y esa lucha era eco de otra más antigua y prolongada, entre, por un lado, las elites partidarias del cristianismo imperial y césaro-papista, que admitía la autoridad suprema del obispo de Roma — la iglesia dogmática y trinitaria-, $y$, por otro, las clases populares de confesión arriana o prisciliana, que eran

\footnotetext{
${ }^{1}$ Emilio González Ferrín niega que hubiera una «invasión» musulmana en el siglo VIII, puesto que todavía no estaba constituido un Estado musulmán expansionista. Hubo una revolución contra el poder imperialista del Estado romano, delegado en los visigodos convertidos al cristianismo trinitario. En Guadalete frente a las tropas visigodas de Rodrigo hubo otro ejército visigodo de los hijos de Witiza, apoyado por una tropa beréber (bárbara), compuesta por diferentes etnias, entre otras, vándalos arrianos que ocupaban el norte de África desde el siglo V, Historia General de Al Ándalus, Almuzara 2006.
} 
defensores de la unicidad de Dios en teología y heréticos desde el punto de vista de la ortodoxia romana.

He subrayado la palabra «revolución». Lo corriente, en las crónicas españolas y la historiografía oficial de nuestra cultura, es hablar de la «invasión» musulmana, para denominar «reconquista» al proceso posterior de expulsión de los musulmanes. Pero se trata de una descripción muy inexacta de los hechos. Ese modo de referirse a los sucesos medievales en la península ibérica es una falsificación histórica. Se trató más bien del hundimiento del Estado visigodo y, en los siglos siguientes, una conversión a la nueva religión musulmana por parte de la población hispanoromana, que era de observancia unitarista — negaba la trinidad de personas en la naturaleza divina- - y se encontraba en una situación de opresión bajo la dominación visigoda, especialmente desde que las elites gobernantes se convirtieran al cristianismo ortodoxo romano en el reinado de Recaredo.

El éxito del islam aquí, como en muchas otras regiones, Oriente Medio, norte de África, centro de Asia, sudeste asiático, etc., tuvo razones históricas, claras y definitivas, que trataré de resumir aquí. Comenzaré por las razones culturales para describir después las económicas. En primer lugar, el islam es una religión tolerante con la discrepancia religiosa, que carece de dogmas y permite la convivencia entre gentes de diferentes confesiones. En cambio, el Estado imperial convertido en Iglesia Romana, comenzó a perseguir disidentes religiosos y a ejecutarlos desde el momento mismo en que adoptó la doctrina cristiana como religión oficial en el siglo IV. La adopción del cristianismo por el Imperio romano fue una «revolución pasiva» en el sentido que Antonio Gramsci da a esa expresión: un cambio en las formas del poder político, que permite a la clase dominante mantener la estructura social de dominación. En muchos lugares del Mediterráneo sur y Oriente Medio, una verdadera revolución cristiana solo llegaría con la victoria del islam.

La intolerancia hacia otras confesiones se manifestaba por la confrontación de los partidarios de la observancia romana contra los arrianos, que provocó la guerra civil entre los visigodos; además de la condena y persecución de la herejía prisciliana, así como la opresión de los judíos de la península ibérica — parece que la designación de «judío» en la época abarcaba también a los cristianos unitarios-. Según dicen las crónicas, estos últimos estaban en una situación muy precaria y fueron un grupo social que ayudó a la victoria musulmana. 
El islam es una versión del cristianismo unitario, corregido y adaptado a los árabes, según afirma el profeta Mahoma en al-Corán —o bien, una herejía cristiana según la opinión del teólogo Juan Damasceno-. Se trata de una religión más racional, pues carece de misterios inexplicables, e impulsa una moral comunitaria y una ética personal racionalista. Entre los mandatos fundamentales de la religión musulmana cuentan normas que se refieren a la higiene, la dieta, la solidaridad, la meditación y la apertura a otras culturas. Mahoma recomendó el estudio, la práctica de la medicina, el cuidado de los débiles, la ayuda a los pobres, el trato humano a los esclavos, la mejora de la situación social de la mujer, etc. Las prácticas religiosas islámicas, partiendo de una interpretación progresista del mensaje monoteísta, mejoraban las costumbres y las instituciones sociales.

La nueva religión también incidió en las relaciones de producción mejorando de forma notable la situación de las clases inferiores, gracias a un régimen más benévolo de exenciones e impuestos del que era portador el feudalismo islámico, en comparación con el sistema feudal vigente en Europa como evolución del Imperio romano. Además el movimiento que dio origen a la civilización musulmana era portador de una revolución agrícola, basada en conocimientos científicos — botánica, hidráulica, farmacopea, etc.—. Lo que permitirá un importante incremento de los rendimientos en los cultivos y la producción de alimentos para el mercado; y esto a su vez condujo a una economía más avanzada en la producción artesanal, una importante actividad comercial que iba desde el Lejano Oriente hasta al-Ándalus y una mejora del nivel de vida entre la población medieval. Acompañando a esa expansión comercial se produjo un flujo cultural de ideas y conocimientos, que facilitó la continuación de la tradición filosófica y científica, desarrollada durante la época helenística en Oriente Medio, Grecia y Egipto.

Esas características explican el éxito de la predicación musulmana al comienzo de la Edad Media, la conversión de extensas regiones al islam y la creación de una nueva civilización progresista que impulsó el desarrollo humano en los siglos centrales del medievo. Desde el punto de vista del desarrollo del pensamiento racional, el progreso económico y cultural aportado por la nueva religión tendrá consecuencias en el terreno científico y filosófico, apareciendo una importante serie de pensadores que constituyeron el periodo más brillante de la filosofía medieval.

La conmemoración de este XIII Centenario de Guadalete debe servir para recordar y afianzar esta tesis. La aparición del Islam en la península ibérica dio 
lugar a una profunda transformación social que tuvo un fundamento económico, pues consiguió un importante desarrollo de las fuerzas productivas, y un aspecto cultural en la adopción de una nueva civilización de carácter científico y racional. Atendiendo a esas razones, podemos asegurar que los siglos centrales de la Edad Media, entre el VII y el XII, fueron una época de progreso económico, científico y cultural, aunque no tuviera su centro en Europa, sino en Oriente. Y es que, si descontamos el ámbito mediterráneo, el pensamiento racional no llegó a Europa hasta el Renacimiento, y eso fue una consecuencia y una prolongación del esplendor cultural de al-Ándalus durante la Edad Media. Como fue subrayado por los arabistas del siglo pasado, especialmente Miguel Asín Palacios, el Renacimiento europeo comenzó en al-Ándalus medieval. ${ }^{2}$

\section{Las raíces sociales e históricas del racionalismo}

Ese efectivo desarrollo económico, social y cultural, conseguido por la revolución musulmana en los siglos VII-VIII y hasta la decadencia del Imperio de los árabes en los siglos XI-XII, ${ }^{3}$ tuvo una expresión intelectual en la reflexión filosófica medieval. El racionalismo es el rasgo más sobresaliente de la filosofía elaborada entre los siglos X y XII por los pensadores de la civilización islámica. Ese modo de pensar manifiesta una confianza en las capacidades humanas, que proviene del importante desarrollo humano alcanzado gracias al orden social, moral y político, que instaura la nueva religión. El racionalismo se expresa, en primer lugar, por la tolerancia hacia las opiniones religiosas, lo que da lugar a una libertad de conciencia que tardará siglos en afianzarse en Europa del norte — mucho más en los reinos peninsulares unificados bajo el Estado español en el siglo XV- Sin embargo, los sabios musulmanes van más allá de la tolerancia, cuando reconocen bajo la aparente multiplicidad de las confesiones religiosas, la existencia de una religión universal fundada en el amor fraterno entre todos los seres humanos. Como reza

\footnotetext{
${ }^{2}$ Es conocida la tesis defendida por este autor, a partir de los estudios de la escatología islámica en Ibn Arabí y su comparación con La Divina Comedia de Dante Alighieri, Miguel Asín Palacios, Dante y el Islam, Madrid, Editorial Voluntad, 1927.

${ }^{3}$ La expresión es de Ibn Jaldún, estadista, sociólogo y filósofo de la historia tunecino del siglo XIV, autor de una Historia Universal. El racionalismo musulmán de la Edad Media le sirve al autor para construir una teoría científica de la historia, basada en la idea de que la reflexión fundada en la experiencia permite a los seres humanos situarse por encima de los animales.
} 
el verso que dejó escrito el teólogo murciano del siglo XIII Ibn Arabí: sólo sigo la religión del amor. Una comprensión de la religión que sería defendida por Rousseau cinco siglos más tarde dentro de la Ilustración europea.

En segundo lugar, en sintonía con esa comprensión de los asuntos religiosos, los pensadores musulmanes ponen la razón por encima de la fe. La razón es la naturaleza común a toda la humanidad; viene a significar la capacidad de diálogo entre puntos de vista alternativos, sobre la base de una coincidencia profunda que nace de las características esenciales de la naturaleza humana como ser social. Dicho de otro modo: la capacidad para crear una experiencia colectiva sumando las diferentes vivencias personales a través de la comunicación lingüística. Todas las creencias son aceptables, en la medida que son expresiones diferentes de esa verdad más honda. Y por ello la razón contiene los criterios para descubrir cuál es la forma religiosa más adecuada a la existencia humana. Como señala al-Farabi en el siglo X —llamado el «segundo maestro» por la tradición filosófica musulmana, el primero es Aristóteles-, el sabio está obligado a practicar la verdadera religión, la que tiene carácter racional, aquélla que cae bajo los criterios de la razón; considerando, evidentemente, que el Islam introducía prácticas morales mucho más sensatas que las creencias cristianas o judías.

Esta afirmación de la superioridad de la razón sobre la fe, tiene una larga tradición en la historia del pensamiento desde Filón de Alejandría en el siglo I, quien explicó el judaísmo bajo conceptos filosóficos. Se trata de una interpretación de los símbolos religiosos, como una forma alegórica de explicar las verdades fundamentales de la razón a un público iletrado de hombres y mujeres, que se dedican a sus ocupaciones cotidianas sin tiempo suficiente para una reflexión ponderada de las realidades esenciales de la existencia humana. Las verdades de la fe son los descubrimientos de la razón explicados simbólicamente al gran público, y la religión es una institución social cuya función es promover la confianza pública en la acción colectiva, afianzando una moral comunitaria. El papel de la religión, desde el punto de vista de la subjetividad emocional de las personas, es crear la confianza necesaria en el orden social para que éste pueda realizarse; el sentido de la fe es la creencia en la buena voluntad de las gentes y en la natural amabilidad del ser humano.

Una desfiguración de esta doctrina, por parte de los clérigos cristianos partidarios de la superioridad de la fe sobre la razón —es decir, irracionalistas e inqui- 
sitoriales_- da lugar a la teoría de la doble verdad, según la cual hay una verdad de la fe y otra de la razón, siendo ambas incompatibles. Pero no es eso lo que dicen los intelectuales señeros de la civilización musulmana. El judío cordobés Maimónides del siglo XIII, que trata ampliamente el tema en su Guía de perplejos, deja claro que se trata de dos formas de interpretar la letra bíblica, una literal — que sirve para ilustrar al pueblo acerca de las verdades racionales-, y otra racional —que explica los símbolos para hacerlos inteligibles—, pero en ningún caso de dos verdades diferentes. En el orden social, el objetivo de la religión es crear comunidad entre los humanos a través de la moral, haciendo posible la convivencia entre los miembros de una sociedad, que se encuentra escindida entre los intelectuales y los trabajadores manuales por la especialización que nace de la división del trabajo.

Por tanto, en tercer lugar, la razón intenta afrontar los problemas de orden social, buscando una solución satisfactoria para todos; el progreso social se funda en la división del trabajo y la especialización profesional, que permiten el incremento consiguiente de la productividad económica, la mejora de los niveles de vida y el crecimiento de la población. Pero esa configuración de la actividad económica produce determinados problemas de organización social, especialmente la aparición de clases y la creación de mecanismos de dominación, que permiten aprovecharse de su situación privilegiada a los grupos sociales encargados de organizar el trabajo colectivo. El pensamiento racional intentará establecer la justicia como objetivo fundamental de la acción política, lo que significa conseguir un orden social armonioso, donde cada miembro obtenga satisfacción de sus necesidades básicas y se eliminen las consecuencias más pesadas de la opresión social.

El punto de vista de la razón está representado por aquel Estado que intenta establecer un orden social justo fundándose en la ley y el compromiso de los actores sociales; representa así la unidad social frente a la pluralidad de las confesiones religiosas. Si bien el Estado islámico tiende a ser confesional, a partir de cierto momento de su consolidación en el siglo IX, está obligado a respetar y proteger la pluralidad religiosa de la sociedad que administra, y en ese sentido es laico en una medida suficientemente amplia para la época. El desarrollo de la cultura judía en al-Ándalus medieval — con un periodo clásico en la producción de la poesía hebrea en Zaragoza durante el siglo XI-, la presencia de judíos y cristianos en la administración estatal alcanzando puestos de relevancia institucio- 
nal -Maimónides como médico del Califa de Egipto, o el obispo Recemundo como embajador del Califa cordobés, por ejemplo-, son prueba de una autonomía de la esfera política respecto de la religiosa, tanto como testimonio de la integración social entre las diferentes comunidades religiosas.

Los intelectuales orgánicos del Estado islámico — sea cual fuere su creenciaconciben la religión como un instrumento para la cohesión social; por su parte, la razón es el lugar donde se encuentran todas las perspectivas sociales en el diálogo común. En orden a configurar el ámbito de la política, la filosofía proyecta un horizonte utópico, la ciudad ideal, que sirve de idea reguladora del orden social existente y al servicio del cual están las instituciones religiosas. Cada comunidad religiosa tiene su propio sistema normativo y los medios para hacerlo cumplir; pero los filósofos medievales, y en primer lugar al-Farabi, establecen una sociedad ideal a partir de la utopía platónica de La República, adaptándola a la religión islámica. La sociedad ideal es la umma, la comunidad de los creyentes, que tiene su modelo en la vida de Medina dirigida por el profeta Mahoma, quien hace el papel de sabio-gobernante. Imitándole, el Califa se rodea de sabios consejeros para el gobierno de los asuntos del Estado, independientemente de la religión profesada.

La ley islámica se establece a partir de esa comunidad ideal, tomando como referencia las costumbres de Medina, y el orden social se funda en el ejercicio de la ley por un cuerpo especializado de jueces que forman el núcleo de la administración estatal. La aplicación de la ley es tradicionalista, se hace teniendo en cuenta los casos anteriores y basándose en la analogía de las situaciones que se van presentando. De ahí que el auténtico clero musulmán — si es que se puede hablar así, pues el islam es una religión sin sacerdotes ni dogmas- sean los jueces en sus diferentes cargos y funciones. El filósofo cordobés del siglo XII, Averroes, pertenecía a una importante familia de jueces andalusíes, lo fueron su abuelo y su padre, y también lo serían sus descendientes. De sus textos podemos colegir los avances sociales que se produjeron en la sociedad musulmana medieval; podemos, por ejemplo, extraer la conclusión de una situación relativamente emancipada de las mujeres andalusíes en la Edad Media, que podían heredar, ser jueces, divorciarse por causa de los malos tratos, salir sin velo a la calle, etc.

El racionalismo es una exigencia intelectual de la justicia social, entendida desde la perspectiva de las clases subalternas; es decir, sobre la base, primero, de 
la igualdad natural de todos los seres humanos — que se plantea como universalidad de la ley_-; y segundo, la acción del gobernante debe ser inteligible para los gobernados. Sobre el fundamento de la universalidad de la ley y reconociendo que el poder político se funda en el consenso de los musulmanes, el sistema judicial en la sociedad islámica tiene la importante función de limitar el poder político del jefe militar — emir o califa-.

Por otro lado, el derecho plantea el problema de la coherencia de las normas, para evitar situaciones contradictorias que conducirían a la parálisis del cuerpo social. Es claro que esa exigencia responde a una necesidad más amplia de la razón humana, de establecer un sistema coherente de ideas que permitan la comprensión cabal del mundo en el que vive. Desde una perspectiva racionalista, resolver el problema de la división del trabajo se plantea como la exposición sistemática y coherente de los conocimientos obtenidos desde diferentes campos del saber especializado — moral, ciencia, arte, religión, etc.—, con vistas a unificar el campo de la experiencia humana, multiplicada por la variedad de situaciones e intereses individuales.

Esa unificación de la experiencia es una exigencia de la razón, que se representa al mismo tiempo en la metafísica como la unidad radical del cosmos. La reflexión filosófica — ya desde Jenófanes en el siglo $\mathrm{V}$ a.n.e. — ha expresado ese problema a través del pensamiento del Uno, la unidad eterna del ser de los entes, raíz creadora de todo lo existente; afirmando sus seguidores de la escuela de Elea que la auténtica realidad reside en el pensamiento, que entiende desde el plano ideal la unidad sistemática del cosmos frente a la diversidad de la experiencia. Esa perspectiva pasará a la filosofía posterior a través de Platón, y el neoplatonismo la desarrollará ampliamente, sirviendo de base para el racionalismo medieval. Esa matriz común de todas las cosas, naturaleza divina que produce toda realidad, es inmanente al cosmos universal, y el monoteísmo se nos muestra como expresión religiosa de una necesidad racional de la existencia social humana.

Por tanto, cuando hablamos de la unificación de la experiencia, no nos referimos a un capricho de la razón — como a veces parecen entender algunos filósofos escépticos-, sino a una exigencia racional, esto es, a una necesidad estructural de la naturaleza humana. Según una visión dialéctica del asunto, la filosofía ha consistido en la construcción de un sistema coherente de proposiciones, que conjugue los conocimientos y las informaciones provenientes de las diferentes 
actividades especializadas. Exigencia que conduce a la metafísica como síntesis filosófica, compendio sumario de la experiencia colectiva que acumulan millones de seres humanos dentro de una civilización, compuesta por el conjunto de sociedades diversas que en una época histórica comparten un determinado grado de evolución. Tal vez el mundo contemporáneo —en la actual descomposición de la existencia racional de la humanidad, inducida por la decadencia del capitalismo liberal — haya renunciado ya a la posibilidad de realizar esa síntesis; pero no está de más conocer cómo se realizó en el pasado, de forma insuficiente y precaria, si se quiere. Como señaló Ortega, la historia es una fuente de experiencia, que debe servirnos para afrontar los problemas del presente.

La civilización islámica medieval representa uno de los grados más altos de evolución humana en su época, si medimos esa evolución desde el punto de vista productivo y científico-técnico, tanto como si lo hacemos desde la perspectiva del desarrollo social y humano. Y en mi opinión, la prueba de ello la tenemos en su filosofía - cuyo racionalismo nos servirá como síntoma o índice del grado de progreso social alcanzado_- Para observar esta cuestión voy a resumir la exposición que Ibn Sina, Avicena, hace de la Metafísica, por ser posiblemente la obra cumbre del racionalismo medieval. ${ }^{4}$

\section{El racionalismo filosófico como expresión del progreso social}

El estudio de Avicena, y especialmente de su Metafísica, fue emprendido por Miguel Cruz Hernández en los años 40 del siglo XX, quien realizó su tesis doctoral sobre este tema. Este autor publicó la traducción de la Metafísica de Avicena que poseemos en castellano desde $1950,{ }^{5}$ después de haber publicado un resumen de su tesis. La explicación que ofrezco a continuación depende completamente de esta versión de la filosofía de Avicena, si bien modifica algunos aspectos de su

\footnotetext{
${ }^{4}$ Avicena reproduce la filosofía de al-Farabi de forma más sistemática: «al-Farabi es el punto de partida de Avicena... Lo que en al-Farabi eran afirmaciones aisladas y a veces sin encadenación lógica, en Avicena se convierte en un sistema ordenado». Miguel Cruz Hernández, La Metafisica de Avicena, Universidad de Granada, 1949. Este texto contiene lo fundamental de su tesis doctoral.

${ }^{5}$ Avicena, Sobre Metafísica, versión y comentarios de Miguel Cruz Hernández, Madrid, Revista de Occidente, 1950.
} 
interpretación. No se trata aquí de enmendar la plana al insigne arabista que abrió camino al estudio de Avicena entre nosotros, así como de numerosos aspectos de la filosofía islámica, sino desde mis modestos conocimientos y desde una perspectiva marxista de la historia, subrayar ciertos aspectos del pensamiento musulmán medieval, poniendo de relieve su importancia para el desarrollo del racionalismo filosófico. Como señaló Ernst Bloch, esa filosofía medieval es el antecedente directo del materialismo dialéctico de nuestros días. ${ }^{6}$

Cruz Hernández explica en su Introducción a la tesis doctoral, que quiere "exponer un Avicena que en todo lo posible sea el inquieto filósofo musulmán que se movió dentro del mundo maravilloso del siglo XI», ${ }^{7}$ evitando una comprensión demasiado dependiente de los prejuicios propios de la cultura occidental. Se trata por tanto de una honrada aproximación a la reflexión avicénica, que al mismo tiempo reconoce la imposibilidad de salirse de un marco de pensamiento propio: "al hacer este modesto trabajo lo he realizado como cristiano». ${ }^{8}$ En respuesta a esa honestidad, mi exposición quiere realizar una interpretación marxista de Avicena, explicando cómo el rasgo más significativo de su pensamiento, el racionalismo ilustrado, hunde sus raíces en el ambiente cultural de progreso económico y social que fue consecuencia de la revolución musulmana del siglo VII. A su vez este artículo es deudor de un estudio más amplio que se ha publicado en Sevilla en $2011 .^{?}$

Ya he señalado que esa revolución, que se produjo en los siglos VII-VIII, tuvo un aspecto económico que consistió en el desarrollo agrícola y la expansión comercial; a su vez tuvo un aspecto político en el combate contra el imperialismo romano - si bien desembocaría primero en la institucionalización del Islam y después con el tiempo en un nuevo imperialismo turco-; en el aspecto cultural merece destacar su tolerancia religiosa y la apertura de ideas al menos hasta el siglo XII, que permitió el desarrollo científico de la Edad Media; finalmente también tuvo un aspecto ético-moral en una serie de normas de solidaridad y apertura social, añadidas a las prácticas higiénicas y la recomendación de la práctica de la medicina. Por esas características, la revolución musulmana fue un factor de progreso

\footnotetext{
${ }^{6}$ Ernst Bloch, Avicena y la izquierda aristotélica, Madrid, Ciencia Nueva, 1964.

${ }^{7}$ Miguel Cruz Hernández, op.cit., 6.

${ }^{8}$ Op.cit., 9.

${ }^{9}$ Miguel Manzanera Salavert, El periplo de la razón, Sevilla, Editorial Fénix (próximo a editar).
} 
social considerable en la Edad Media, y tuvo su expresión cultural en el desarrollo de una filosofía racionalista admirable en muchos aspectos, y que fue el antecedente directo del desarrollo cultural europeo a comienzos de la modernidad.

La labor más importante y reconocida en «occidente» de esos dos grandes filósofos musulmanes que fueron Avicena y Averroes, fue precisamente su estudio y desarrollo de la ciencia médica. Una ciencia de la salud que tenía carácter preventivo, pues se basaba en la higiene y la dieta, así como el uso medicinal de las plantas; el complemento de la medicina islámica es una farmacopea basada en la botánica y el conocimiento de las propiedades curativas de las plantas. Considero que ésta es la razón por la que debemos considerar que la metafísica de Avicena es una proyección metodológica y epistemológica de los fundamentos de su práctica médica. A su vez la recepción de la filosofía de Aristóteles se hace desde esta perspectiva, reconociendo la ciencia biológica como la base de sustentación de su filosofía.

En este sentido, los conceptos fundamentales de esa metafísica intentan describir lo que hoy en día conocemos como funcionalismo o método funcional, mediante la construcción de los conceptos de estructura y función. Esa metodología tiene su clave en el holismo aristotélico: el todo es mayor que las partes, y modernamente se traduce por el concepto de emergencia: la aparición de propiedades nuevas en la historia natural del universo, a partir de estructuras orgánicas de elementos heterogéneos que interactúan sistemáticamente entre sí. La vida sería una propiedad emergente de la materia inorgánica, y el ser social a su vez sería una emergencia de la materia orgánica. Las propiedades emergentes que caracterizan el ser vivo son el crecimiento, mediante la absorción y acumulación de la energía solar, y la reproducción, gracias a los mecanismos que acumulan y transmiten información a través de las moléculas genéticas. Por su parte las propiedades emergentes del ser social son: el lenguaje y la representación conceptual del mundo material; el mundo de los valores y los ideales, que son criterios compartidos socialmente para evaluar la experiencia sensible; la conciencia personal, como instancia que realiza el juicio crítico, es decir, la evaluación de la experiencia a través de los ideales.

La visión del mundo de la civilización musulmana medieval, que realizó una revolución agrícola y estableció una moral fundada en la salud preventiva, debe haberse centrado en la comprensión de los procesos biológicos y medioambientales, y su filosofía dará cuenta de esa realidad. Por eso, la filosofía de Avicena refleja una visión funcionalista del cosmos, que toma como referencia la metafí- 
sica de Aristóteles, reelaborada desde la perspectiva del neoplatonismo. Éste fue desarrollado entre los siglos III y VI, y pervivió bajo la religión cristiana en formas heréticas de enorme calado histórico; si bien fuertemente reprimido, el neoplatonismo acabó siendo uno de los factores principales que dio origen a la religión musulmana - y a la revolución social que dio origen a esa avanzada civilización que fue el Islam medieval一.

\section{La estructura básica de un cosmos racional}

El papel que juega el sabio musulmán en el Estado islámico, es parecido al que realizó el filósofo estoico bajo el Imperio romano: es un alto funcionario que ocupa los puestos de mayor responsabilidad, consejero junto al Emir o el Califa — los jefes militares del sistema administrativo- . De ese modo se cumple el orden de la república platónica, donde el sabio ejerce el papel gobernante. Así vemos aparecer a al-Farabi junto al Califa de Bagdad, a Avicena en la corte de los reyes persas, o a Averroes encumbrado por el Califa almohade. Se trata de un Estado que quiere ser un despotismo ilustrado al servicio del pueblo llano, entendiendo que el poder político nace del consenso entre los musulmanes. Y la filosofía cumple el papel de ofrecer una visión del mundo coherente y racional al dirigente del orden social. Se trata de la ideología de la clase dominante en una sociedad que se desarrolla de modo progresivo, aumentando sus conocimientos científicos y desarrollando las fuerzas productivas.

El cosmos es concebido como un organismo compuesto por un sistema de funciones diferentes y que tiene un principio activo de carácter espiritual, el Alma del Mundo, responsable de su movimiento armonioso. Hablar del carácter espiritual no equivale a especular con un mundo sobrenatural, como hace la teología cristiana, ${ }^{10}$ sino mostrar la emergencia de una ontología nacida de las relaciones sistemáticas entre los elementos del todo. Heredera del sistema neoplatónico, esa

\footnotetext{
${ }^{10}$ Aunque como se ha señalado en la nota 2, la religión islámica concibe la vida de ultratumba de una forma muy similar a la cristiana, Avicena rechaza la resurrección de los muertos, así como los tormentos eternos para el alma, entendiéndolo como una forma metafórica de hablar. Esa perspectiva había sido adoptada por Orígenes, filósofo cristiano del siglo III influido por el neoplatonismo, para quien toda la creación debe volver a reunirse con su creador tras un largo proceso de alejamiento, plagado de sufrimientos por la carencia del Ser Necesario.
} 
metafísica piensa lo espiritual como una realidad inmanente al universo físico. «Alma» tiene un sentido racional, elaborado por la metafísica clásica antigua, como principio del movimiento y garantía de unidad en un cuerpo orgánico. Esa Alma del Mundo es una emanación de la realidad absoluta, el Uno Divino, concepto que expresa la naturaleza unificada de todas las cosas. Así pues la divinidad espiritual no existe de modo trascendente en un más allá de la naturaleza, sino que es una realidad inmanente al mundo cósmico que habita el ser humano. ${ }^{11}$

Esa divinidad es Ser Necesario, eterna realidad existente, su esencia consiste en existir; desde su sobreabundancia de ser emana el universo entero: el mundo supra-lunar, en el que las inteligencias puras rigen los destinos de las esferas celestes, y el infra-lunar de los cuerpos naturales que son educidos de la materialidad por el movimiento celeste. La teoría astronómica encaja con la explicación metafísica de la naturaleza. Pero el objetivo de la metafísica es más formal: investigar y precisar el código lingüístico en el que se transmite la información, tanto la científica como la normativa. Para ello establece una serie de distinciones analíticas: materia/forma, substancia/accidentes, alma/cuerpo, esencia/existencia, univer$\mathrm{sal} /$ particular, actualidad/potencialidad, necesario/contingente, que sirven para diseñar una ontología capaz de explicar la complejidad del universo y su comprensión por la inteligencia humana.

Pero Avicena es consciente de que esas distinciones no tienen un carácter absoluto más que en la mente humana. La realidad natural se produce como una composición sintética de las antítesis analizadas por la inteligencia humana:

- lo que tiene existencia real es una forma material, donde la forma no puede existir sin la materia - a menos que sea una Inteligencia, substancia separada cuya actividad consiste precisamente en captar las formas de los objetos reales-.

${ }^{11}$ Según la filosofía neoplatónica no podemos conocer la realidad divina en términos racionales, pero sí que podemos deducir racionalmente lo que no es: no hay la más mínima carencia en el Ser Necesario, todo en Él es plenitud. Pero del mismo modo que el Uno es por sí mismo la existencia, toda existencia es divina, participa del Uno; de ahí que pueda haber un acceso intuitivo a la divinidad desde la interioridad humana, lo que abre el camino de la mística, tan extendida en el mundo musulmán a través de los sufíes, que el propio Avicena transitaría. 
- esencia y existencia se distinguen perfectamente en los seres contingentes, pues sólo la esencia del Ser Necesario consiste en existir; pero toda esencia tiene alguna forma de existencia — aunque sea meramente intencional como idea-, dado que los entes del mundo creado son contingentes por sí, pero necesarios por otro, en cuanto que el Ser Necesario crea necesariamente la realidad de forma determinista.

- el cuerpo es una estructura funcional y el alma es la propiedad emergente, pero es claro que lo uno no existe sin lo otro - como nos muestra la muerte física: Avicena no aceptaba la resurrección de los muertos-

- el universal es una forma conceptual de la mente: no hay entidades colectivas y la existencia corresponde a lo individual, ya sean los objetos materiales concretos, o bien las inteligencias que contienen las formas separadas y son también individuales.

Etc. La metafísica de Avicena no concede más realidad que la conceptual a esas distinciones, y comprende el mundo físico bajo la síntesis de los aspectos analizados. Si bien existe una jerarquía de las substancias: la forma, por ser en acto, tiene una prioridad existencial sobre la materia, que es potencia; pero la metafísica de Avicena subraya la substancialidad de la materia, creada pero eterna. La materia es el receptáculo del ser, y su concepto representa la potencialidad para ser que reside en el mundo natural; y aunque Avicena reconoce la función de la materia como principio de individuación, subraya su aptitud para ser un componente imprescindible de la forma material, y sitúa tanto en la materialidad como en las formas, un deseo por la existencia que observa en el mundo de la naturaleza. Esa disponibilidad natural será encauzada por el Alma del Mundo para realizarse en la existencia; y el mal no es más que la frustración de esa potencialidad de las cosas para ser en la plenitud de su esencia.

Avicena, siguiendo a al-Farabi, distingue esencia y existencia en las cosas. La esencia son los rasgos que definen una realidad. Pero la existencia es extrínseca a la esencia, y todo lo que no tiene el ser en su esencia lo tiene por otro. Las cosas posibles no merecen la existencia, prescindiendo de su relación con el Ser Necesario que crea la realidad por sobreabundancia de su ser existencia. Sin embargo, la realidad del Ser Necesario es inmanente, existe en la realidad que crea, y por eso el Ser Necesario necesita de todo lo que existe a partir de Él. Como consecuencia esa creación es determinista: el Ser Necesario produce el universo por 
una característica intrínseca a su naturaleza de existencia plena, no por un acto de voluntad consciente. No hay libertad divina en el sentido humano de decidir la acción y sus objetivos previstos; su creación es necesaria. La metafísica de Avicena elimina el carácter antropomórfico que poseen los rasgos divinos en la mentalidad primitiva - y en el cristianismo dogmático- - Por tanto, el Uno como causa eficiente del universo, pone en marcha una producción predeterminada de la realidad cósmica, que no puede ser de otra forma a como es.

Las substancias separadas no existen unidas a la materia y son Inteligencias cósmicas —o bien pueden ser entendidas como ángeles puros—; su esencia no coincide con su existir y existen por el Ser Necesario. De ahí que otros autores posteriores —entre ellos el judío andalusí Ibn Gabirol o Avicebrón—, dirán que también esas Inteligencias son portadoras de materialidad en cuanto que, no poseyendo la existencia de por sí, esa materialidad es la marca de su posibilidad para ser. Entonces se interpreta que las Inteligencias residen en las esferas celestes que rigen en su movimiento perfecto y eterno, constituyendo éstas su cuerpo material. El materialismo metafísico se combina así con la cosmología científica y la astronomía matemática, para dar una visión coherente del mundo natural.

Como he señalado, Avicena defiende una metafísica conceptualista; define los universales, ya como la idea que se predica de varios objetos reales diferentes - concepto formal_ - ya como la idea que no se refiere a ningún existente en acto - pero tiene una existencia intencional en el espíritu-. Admite la existencia del universal en el intelecto, como la forma que tiene en la inteligencia una relación de multiplicidad, pero no en los individuos que tienen su existencia como realidad concreta. Lo común a varios individuos es una mera realidad mental, y esta realidad viene explicada por el concepto de ser intencional como una forma de existencia subjetiva, ya sea en la facultad estimativa, ya en la inteligencia. Además de contener los criterios por los que se produce el juicio que nos merece la realidad, lo intencional es concepto, universal al tiempo que numéricamente uno, y se corresponde con el resultado de la abstracción de las ideas a partir de la experiencia sensible. Hemos de concluir que la abstracción está dirigida por la intencionalidad, por los objetivos del conocimiento humano. Ahora bien, los objetivos del conocimiento humano no están puestos por la conciencia individual; esa abstracción es realizada por la Inteligencia Activa o Intelecto Agente, que es una entidad que ilumina la mente humana, como la luz del sol ilumina la tierra a oscuras. La idea proviene de la teoría de la abstracción de Aristóteles, ree- 
laborada por Alejandro de Afrodisia en el siglo II, quien postula el entendimiento agente como una entidad colectiva e inmortal, capaz de producir las ideas que son recibidas por ser humano individual, quien posee un entendimiento paciente o memoria personal para conservarlas.

Por tanto, el racionalismo musulmán afirma la existencia de ideas innatas, o mejor dicho, la existencia de ideas que produce el entendimiento con total independencia de la vida sensible y corporal. Así la Metafísica de Avicena comienza con un pasaje fantástico en el que se nos dice que una persona cualquiera, desposeída de toda sensibilidad corporal, una mera conciencia pensante, llegaría a la conclusión de su propia existencia, y por tanto a la idea del ser. Se trata de la deducción — que repetirá Descartes en el XVII—, del principio universal del sistema filosófico: la idea de «ser» —en el sentido de existencia—, es innata y evidente, equivale a la idea de divinidad necesaria y da comienzo al sistema deductivo de la metafísica; a partir de ese principio y a través de definiciones y distinciones analíticas, se establecen los conceptos básicos para la investigación científica y el fundamento de toda normatividad racional.

Los principios metafísicos no son abstraídos desde la sensibilidad; son producidas por la entidad cósmica, que ilumina el entendimiento de los seres humanos para darles los instrumentos de comprensión de la realidad. Eso significa que los conceptos abstractos son universales y compartidos por todos los seres humanos. La doctrina del Intelecto Agente puede parecer oscura, pero en realidad no lo es, si aceptamos su carácter metafórico. Pues como señala Avicena en su Metafísica, todas las lenguas — todos los países y todas las naciones — poseen los términos para nombrar las realidades fundamentales, lo que de alguna manera nos está mostrando la intuición de que la producción de ideas en el entendimiento humano es una consecuencia de sus capacidades lingüísticas, de que existen universales lingüísticos comunes para todos los hablantes y esos universales nos muestran los rasgos fundamentales de la realidad. En mi opinión debemos entender esa especie de ser mitológico que es el Entendimiento Agente de la filosofía racionalista medieval, como el lenguaje que sirve para la comunicación humana y a partir del cual se forman las ideas y conceptos que usamos para manejarnos con la realidad. ${ }^{12}$

\footnotetext{
${ }^{12}$ Avicena muestra una conciencia lingüística de los conocimientos y los conceptos fundamentales al principio de la Metafísica $\$ 3$, cuando afirma que la escritura indica la palabra, la palabra designa la forma imaginaria, y la forma imaginaria representa a la cosa. A continuación añade
} 


\section{La explicación teleológica y la moralidad}

A través del concepto del ser intencional se plantea el problema crucial de una ética racional fundada en la libertad, que estriba en el hecho de que la acción humana está planificada hacia una finalidad previamente decidida. La metafísica avicénica utiliza una clave aristotélica traspuesta a la lengua semita para expresar la cuestión: la causa final es la causa eficiente de la causa eficiente — podríamos traducir: la causa final es la causa por antonomasia, en grado de excelencia-. Es decir, el mundo está orientado hacia un objetivo o meta en la plenitud del ser; pero esa finalidad que rige todo el movimiento cósmico es necesaria, no hay una persona divina que la escoja o decida — ni mucho menos tres- El Uno divino no tiene afecciones, consiste en la tranquila contemplación de su esencia luminosa; las afecciones pertenecen a los seres contingentes por sí mismos, que aman la existencia: todas las cosas tienden al ser por su deseo natural y su amor innato, y este deseo es la causa de su existencia. El sujeto activo del movimiento creador son los seres, naturales y espirituales, en cuanto que están motivados a existir por una pasión de ser; si bien éstos carecen de la potencia creadora de sí mismos y reciben la existencia del Ser Necesario como un bien gratuito. Y cuando ese deseo de ser se frustra, aparece el mal.

El cosmos responde a una teleología objetiva, sin sujeto, determinada por la creación necesaria — proveniente de una divinidad que no es personal-. Se trata de una explicación mítica del concepto de función: actividad que realiza un elemento dentro de una estructura, actividad que es necesaria para que esa estructura se mantenga. Esa concepción determinista del devenir cósmico y de la acción humana, proviene del neoplatonismo y reproduce la visión estoica del mundo; parece propia de los dirigentes políticos del Estado, en cuanto contemplan la sociedad que gobiernan como un todo estructurado por sus funciones.

Desde la perspectiva ética, tal conceptualización de la finalidad objetiva tiende al intelectualismo, descubriendo los factores que condicionan la conducta humana bajo la aparente libertad de elección: el mal proviene de la ignorancia

que esa capacidad referencial del lenguaje no difiere según los países y naciones, luego es un rasgo esencial de la naturaleza humana. Por otra parte, ese postulado tiene un trasfondo religioso: la religión musulmana gira alrededor de al-Corán, la palabra revelada, en sintonía con el Prólogo del Evangelio de Juan: al principio existía la Palabra. 
de sí mismo y de las ilusiones de la conciencia. Se opone a la doctrina del libre albedrío, que viene inculcada por la enseñanza religiosa eclesial - y cuyo objetivo es promover un desconocimiento de sí misma para una conciencia manipulable y manipulada - La resolución determinista del cosmos niega el libre albedrío, dado que la creación es concebida como una actividad necesaria del Uno divino.

Maimónides, discutiendo esta cuestión, afirmará que la realidad cósmica es determinista según la sabiduría, pero es necesario explicar el libre albedrío al pueblo para que las personas actúen de modo responsable. Del mismo modo que la verdad racional no coincide con la religiosa, la interpretación subjetiva de la vida moral está en función de la calidad ética de la persona: la comprensión determinista del cosmos es válida para el sabio, que ha profundizado en el conocimiento de la realidad a través de la meditación sobre sí mismo, pero no para el hombre vulgar que se desconoce a sí mismo y no puede conocer las verdaderas causas de sus acciones, pareciéndole así que actúa «libremente», sin condicionamientos externos, cuando desea la posesión de las cosas. Como en la explicación de las relaciones entre fe y razón, aparece aquí una clara consciencia de la división de la sociedad en clases, dedicadas a tareas diferenciadas, intelectuales unas - los funcionarios del Estado—y manuales otras —el pueblo trabajador—.

Éste es otro aspecto de aquella teoría de la doble verdad, que tanto repugna a los teólogos cristianos. Pero Maimónides no está defendiendo una doble moral, sino una moral única que se alcanza de modos diferentes, según los temperamentos y posibilidades de las personas - especialmente en función de la posición de clase- También aquí se nos muestra que la desconfianza de la clerecía romana hacia la razón, reside en un proyecto de manipulación de la conciencia a través de los sacramentos. El conocimiento de sí mismo como fundamento de la emancipación personal — que es el mandato fundamental de una ética racional-, es anatema para el cristianismo dogmático.

Por el contrario, desde un punto de vista moderno debemos reconocer que ambas formas de teleología son conceptos válidos y complementarios para la interpretación de la realidad humana: la finalidad necesaria del funcionalismo —reconociendo los condicionamientos que mueven nuestra acción social—, y la finalidad intencional de la moral — como ámbito de las decisiones conscientes-; pero sólo desde un conocimiento suficiente de esos condicionamientos se 
hará posible la decisión racional y el acceso a una libertad auténtica. ${ }^{13}$ El marxismo ha intentado una explicación de la historia que combina ambas: el desarrollo necesario de los acontecimientos históricos, gobernados por las leyes deterministas de la historia, es el entramado sobre el que puede alzarse la libertad humana, superando el reino de la necesidad. El ser social es una emergencia en la historia natural de la Tierra, pero el ser ideal que emerge de la historia humana se encuentra todavía en trance de constituirse.

Si Avicena escoge la teleología necesaria, funcionalista, para definir su posición metafísica es, primero, porque sobre todo está ocupado con los procesos biológicos y concibe el cosmos desde el punto de vista de los fenómenos vitales; y segundo, porque es la visión adecuada para el gobernante político, pues al reconocer los condicionantes de sus decisiones debe evitar la arbitrariedad en el ejercicio de su cargo. La existencia en el espíritu de un ser intencional, ya sea en la facultad estimativa — valores e ideales—, ya en la inteligencia — conceptos-, ese ser intencional — no existente en sentido absoluto, pero que puede existir en el espíritu - es el fundamento de la libertad humana como creación de un mundo de ideas más allá de las constricciones de la naturaleza material. La libertad es, en un primer momento, comprensión racional de la necesidad — como diría Spinoza para la época moderna-.

\section{El antirracionalismo como síntoma de decadencia social}

En la problemática medieval de la filosofía podemos encontrar algunas cuestiones que continúan siendo fundamentales para la vida humana en la tierra. También el escepticismo propio de nuestra época tiene un referente en la filosofía musulmana medieval. En el siglo XI apareció un filósofo persa, Algazel, que se empeñó en derribar el edificio racionalista, con no menos virulencia y acritud que emplearían algunos filósofos europeos contemporáneos — descontando la permanente actividad de los teólogos católicos romanos, seguidores del tradicional irracionalismo religioso al servicio de glorias imperiales-. Quizás no haya nada que nos certifique con más claridad el final de la revolución musulmana

\footnotetext{
${ }^{13}$ Ambas formas de finalidad coexisten en la misma persona según el mandato moral de una ética puesta al día por Hegel: llega a ser quien eres.
} 
—y la era de progreso y desarrollo que trajo al mundo medieval—, que ese filósofo escéptico insistiendo con radicalidad y pasión merecedoras de mejores causas, en que la razón no puede conocer la realidad, y en que un hombre bueno y sabio sólo tiene una cosa que hacer en el mundo: buscar un Dios transcendente con todas sus fuerzas.

La crítica de la noción de causa - como producto de la costumbre basada en la experiencia_, la imposibilidad de establecer leyes universales — para defender la libertad omnipotente de un Dios que pueda obrar milagros en cualquier momento-, la comprensión de la ciencia como mero indagar empírico —afirmando la falsedad de principio de toda hipótesis teórica一, etc., constituyen un ataque en toda regla contra el racionalismo fundado en la ciencia, y desembocan en la primacía de la fe sobre la razón y de la teología sobre la filosofía. La escuela teológica mutazilí de carácter racionalista, que había sido impulsada por los gobernantes progresistas del Califato de Bagdad en los siglos de efervescencia racionalista, fue sustituida por la teología de la escuela asariya de Basora, cuya filosofía ocasionalista deja toda la realidad en manos de un dios personal que gobierna cada uno de los acontecimientos naturales y crea continuamente el universo.

Algazel ha pasado a ser el filósofo y teólogo más apreciado en el mundo musulmán, y su influencia inmediata hizo desaparecer la tendencia racionalista en la cultura musulmana. No importa que Averroes refutara su anti-racionalismo, pues sus libros tuvieron que sufrir la persecución de los funcionarios del Estado almohade: Averroes no ha sido conocido en el mundo islámico como filósofo, sino como jurista. El éxito de Algazel es un síntoma de la época en que vivió. Su labor se parece a la de Hume mucho más que a la de cualquier teólogo católico de la época —apoyándose en el brazo secular para reprimir la herejía-. La persecución del hereje por sus opiniones religiosas no es posible en el mundo musulmán, donde no hay dogmas ni clérigos, sino solo leyes y jueces. Cierto que hubo persecuciones; pero éstas tenían un carácter político más que religioso: la escuela masarrí en al-Ándalus, o los Hermanos de la Pureza en el Califato de Bagdad, tenían un carácter radical en su defensa de la soberanía popular y la crítica de la propiedad privada que les hizo antipáticos a los gobernantes. Cierto también que a partir del siglo XI, por doquier aparecen quemas de libros, en Sevilla, en Córdoba o en Bagdad — los escritos de Ibn Hazm, la Enciclopedia filosófica de los Hermanos de la Pureza, los textos de Averroes, etc.- Ese con- 
servadurismo proviene de la creación de un Estado burocrático con su casta de funcionarios conservadores e integristas, instalados en sus prerrogativas y privilegios que defienden con saña. ${ }^{14}$ Pero no hemos de olvidar que los filósofos racionalistas de la época clásica medieval eran altos funcionarios de la administración estatal. Por tanto, el descrédito de la razón no puede hacerse a través de la represión, sino mostrando sus errores y limitaciones, reduciendo sus alcances y resultados. En esto también, la cultura musulmana es un claro precedente de la modernidad europea.

Tal vez no fuera ajeno a ese proceso de decadencia el ataque que los reinos cristianos europeos van a comenzar en el siglo XI contra la civilización islámica, las Cruzadas. La presión militar, impulsando la creación de un fuerte ejército, se sumaba al final del impulso progresista de la revolución musulmana y a la construcción de una administración burocrática como estructura fundamental del Estado califal. Esos factores de conservadurismo social dieron lugar a una coyuntura histórica que se expresó intelectualmente a través del misticismo anti-racional de Algazel. Ese «asalto a la razón» que se produce en el siglo XI manifiesta, pues, el final de la revolución musulmana; certifica una profunda desconfianza en las capacidades humanas y es así el síntoma de que el modo de producción ha alcanzado el máximo de sus posibilidades, entrando en decadencia. Al cabo de los siglos el brillante feudalismo árabe sería sustituido por el Imperio turco, estructura militarista y a la larga genocida, en amarga sintonía con el imperialismo romano césaro-papista contra el que había combatido la revolución musulmana. El feudalismo árabe había servido para desarrollar las fuerzas productivas durante unos siglos, hasta que entró en decadencia hacia el siglo XI.

Ese estancamiento de la civilización musulmana al final de la Edad Media tuvo por consecuencia un desplazamiento del centro de desarrollo intelectual hacia Europa: gracias a la conquista de Toledo por Alfonso VI en 1085 el pensamiento musulmán fue transvasado a Europa, a través de sucesivas generaciones de la Escuela de Traductores de Toledo en los siglos XII y XIII, y se pusieron así las bases para el futuro Renacimiento europeo. Oxford, París, las ciudades ita-

\footnotetext{
${ }^{14}$ Andrés Martínez Lorca en su Averroes. El sabio cordobés que iluminó Europa, Córdoba, El Páramo, 2010, ha explicado cómo la persecución de Averroes en los últimos años de su vida, llegando a la quema de sus libros en el 1196, tuvo como origen las envidias e intrigas de los funcionarios cordobeses.
} 
lianas y los conventos alemanes, fueron las continuadoras del legado musulmán. La metafísica de Avicena se fundió con el agustinismo franciscano para dar origen a la primera investigación científica europea en la Universidad de Oxford del siglo XIII. La influencia de Averroes fue persistente en Europa durante el final de la Edad Media, hasta el punto de que Tomás de Aquino tuviera que escribir sus libros contra el llamado «averroísmo latino». El formato aristotélico de los estudios científicos en la universidad europea se introdujo a través de las obras de Averroes traducidas desde Toledo. Avicebrón fue intensamente leído siendo origen de herejías panteístas fuertemente reprimidas por la Iglesia. No obstante y a pesar de ello, podemos ver en su filosofía el origen de la corriente de pensamiento que conduce a Giordano Bruno y Spinoza.

Y curiosamente, las ideas de Algazel sirvieron de parapeto nominalista a los científicos europeos del siglo XIV. Esa crítica a la razón que supone el final del progresismo musulmán, toma un significado completamente diferente en el contexto europeo controlado por la iglesia romana: la posibilidad de seguir investigando sin tocar los dogmas de la fe, admitiendo la superioridad de la fe sobre la razón. El movimiento nominalista — Ockham, Autrecourt, Oresme, etc.— adoptó ese punto de vista escéptico para escapar a la persecución religiosa de la razón y la ciencia moderna en el final de la Edad Media. Oresme pudo intuir la hipótesis heliocéntrica dos siglos antes que Copérnico, si bien negando que pudiera ser real.

Las obras médicas de Avicena y Averroes son textos clásicos de lectura obligada a lo largo de todo el Renacimiento. En la Europa ya renacentista, la ciencia —astronomía, física, alquimia, botánica...-, el arte y la literatura, bebieron de fuentes árabes y se construyeron sobre los cimientos de la civilización islámica. La revolución burguesa empezó a tomar el relevo al feudalismo en decadencia, y la antorcha del progreso pasó de Oriente a Europa.

\section{7. ¿Qué son los conceptos racionales de la metafísica?}

Esta interpretación del desarrollo de la civilización musulmana, que se ha intentado aquí, pretende ser una aplicación de los presupuestos marxistas de la historia. Si la historia humana se nos muestra como una alternancia de etapas de progreso y decadencia, es claro que la reflexión humana sobre esa historia nos proporcionará tanto una metafísica racionalista confiada en el progreso, como 
una visión irracionalista que muestra la banalidad del mismo. Pero para terminar este breve resumen de la actividad filosófica en el mundo medieval, tal vez pueda ser interesante extraer alguna moraleja a modo de conclusión, más allá de la evidente intención del autor, de verificar la teoría marxista a través de la defensa del racionalismo filosófico. La pregunta que encabeza esta sección tiene como finalidad plantear el sentido que hoy en día puede tener la metafísica racionalista, atendiendo al papel que la hemos visto jugar en el pasado.

Una interpretación de la tradición aristotélica nos muestra que la metafísica sirve de fundamento al análisis formal del código lingüístico, de modo que se pueda transmitir la información críticamente elaborada en diversos campos de conocimiento y acción humana. Esa información se refiere a rasgos básicos y generales del mundo natural y humano, a situaciones continuamente repetidas de la acción humana - lo que podríamos llamar las estructuras constitutivas del ser social— , de modo que tal información permita alcanzar un determinado grado de coherencia, utilizándose en contextos muy diferentes. La filosofía elabora síntesis consistentes de proposiciones analíticas y afirmaciones de principio, cuyo fin es servir de marco a múltiples tareas intelectuales, que incluyen la investigación científica del mundo natural y social, la interpretación de los símbolos religiosos y artísticos en general, y la producción de sistemas normativos que rijan la organización social justa.

Una tarea que hoy en día muchos consideran demasiado exigente e imposible de completar. Pero tal vez eso se deba a que el racionalismo esté pasado de moda, en una sociedad que cada día nos da signos incrementados de agotamiento y decadencia. Especialmente ese irracionalismo parece fundarse en una confusión entre el contenido y la forma. Averroes contestó la crítica de Algazel, y entre otras cosas ya en el siglo XII señaló lo que Kant respondería a Hume en el XVIII: es cierto que la noción de causa pertenece a las ideas humanas, es una costumbre y es dudoso que exista en la realidad natural algo que podamos identificar como causa, pero los seres humanos tenemos esa forma de conocer la realidad para manejarnos con ella, no hay nada malo en ello, mientras sea útil para nuestros propósitos. Es nuestra forma de conocer el mundo.

Ambas posiciones coinciden en reconocer los límites del conocimiento humano; pero la actitud hacia ese reconocimiento es diferente: Averroes se apoya en él para desarrollar su metafísica racionalista, que tiene por objetivo fundamen- 
tar la moral y la política como fruto del consenso entre los musulmanes. Algazel se refugia en la mística: sin renunciar al conocimiento científico, remite la vida moral a la religión revelada y la política a las decisiones del gobernante.

La tradición marxista del pensamiento moderno ha centrado el desarrollo filosófico en la lucha entre corrientes opuestas, representando las visiones del mundo de las clases subalternas: materialismo versus idealismo (Lenin), racionalismo versus irracionalismo (Lukács) — por citar dos de las versiones más conocidas del tema- La crítica marxista posterior ha reconocido que esa simplificación recorta el devenir de la filosofía a un esquema sin vida (entre nosotros Sacristán), especialmente cuando se interpreta desde el punto de vista maniqueo del bien y del mal. Un mejor conocimiento de la historia, y en especial el estudio de los acontecimientos medievales, nos arroja cierta luz sobre el presente desde el lejano pasado. Cierto que el materialismo y el racionalismo vienen asociados en la visión de las clases subalternas — ¡incluso cuando esa visión está organizada por las formas religiosas!_- Cierto que la comprensión científica de la naturaleza y la revolución tecnológica en la producción, se producen en sintonía con la actividad revolucionaria de los trabajadores y las clases medias en la construcción de una nueva sociedad más justa. Cierto, por otro lado, que el irracionalismo filosófico se corresponde con épocas de estancamiento e ideologías opresoras, excluyentes y explotadoras. Cierto que el sobre-dimensionamiento del mundo espiritual sobrenatural viene a desvalorizar — de modo peligroso, no nos engañemos - la vida sencilla de las gentes del pueblo. Exageraciones evidentes aparte — peligrosas cuando son asimiladas por mentes sectarias y dogmáticas_esas intuiciones de los clásicos marxistas parecen demostrar suficientemente su validez. Conviene no olvidarlas en tiempos de craso escepticismo, rayano en el cinismo más desvergonzado y menos ético — nada que ver con Diógenes el perro-. Pero tampoco podemos olvidar los límites incuestionables que condicionan la acción humana en el mundo que habitamos, y que son la causa efectiva de tanta desilusión contra la razón. Quien espera demasiado, vive de ilusiones, y corre el riesgo de tropezar en la más leve contrariedad.

Nuestra época nos pone ante el reto de reconstruir el racionalismo, cuya forma moderna es el materialismo dialéctico, aunque tal y como están las cosas pueden pasar siglos para que ese racionalismo tenga sentido histórico. Para ello habrá que tener en cuenta el sentido clásico de razón como término medio entre dos extremos. Criticando el pecado del extremismo que tantos bienintencionados 
redentores han cultivado con ardorosa impaciencia. No podemos entender el marxismo, sino desde aquella advertencia de Walter Benjamin: el término medio es el comunismo, lo extremista es el capitalismo. Creo que esa lección está contenida en la revolución musulmana medieval y la metafísica racionalista que se inspiró en ella.

Eliminar ciertas confusiones heredadas del progresismo ilustrado es necesario en nuestra época. Queda claro cómo la revolución islámica se enquistó a largo plazo, en el Estado burocrático creado a partir de ella, lo que dio origen a la decadencia de la civilización musulmana desde el siglo XII. Ése es el sentido político del "giro irracionalista» de la filosofía musulmana desde Algazel —parece ocioso mostrar paralelos en nuestra época- Y Y si bien Algazel buscó una alianza con el misticismo religioso en contra del racionalismo, sin embargo, esa alianza no tiene ni mucho menos la naturalidad que parece otorgarle el progresismo moderno; muchos místicos sufíes — como las escuelas ya citadas de Ibn Masarra en al-Ándalus y los Hermanos de la Pureza en Oriente- fueron progresistas y racionalistas oponiéndose a ese Estado represor creado finalmente como decantación de la revolución religiosa - lo que supuso también la decadencia de los árabes-. El misticismo sufí proviene del neoplatonismo helenista, y su práctica puede explicarse racionalmente por sus objetivos éticos y morales.

El punto fuerte del racionalismo será que todo tiene un sentido por descubrir; incluso la propia falta de sentido puede ser explicada: el irracionalismo es un momento del descubrimiento de la razón; el triunfo de una ideología irracional indica la insuficiencia del progreso alcanzado, o bien la inadecuación del camino emprendido. Pero no se debe confundir irracionalismo con espiritualismo; éste es un camino para la transformación de la vida interior: la filosofía debe transformar el mundo — al decir de Marx-, pero a veces el mundo que tiene que transformar reside en el interior del alma humana. En un momento en que la civilización capitalista liberal entra en profunda decadencia, conviene echar un vistazo a lo que otras civilizaciones tienen que decirnos, pues a lo mejor los problemas de la humanidad actual tienen su solución en ellas. La conclusión de esta investigación sobre la filosofía medieval, es que las ideas filosóficas son tanto los índices de necesidades objetivas de la humanidad y la exposición sintética de las experiencias históricas, como el planeamiento futuro de la realidad humana. El racionalismo es expresión de una época progresista y conquistadora: así lo fue en la Edad Media entre los musulmanes, y también lo ha sido en los últimos 
tiempos con el marxismo respecto a la revolución burguesa. Por eso decía Ernst Bloch en su libro sobre Avicena, que el racionalismo materialista de los filósofos musulmanes era el antecesor del materialismo dialéctico del siglo XX.

\section{Bibliografía}

Al-Farabi (1985). La ciudad ideal, presentación Miguel Cruz Hernández, Madrid: Tecnos.

Averroes (1996). Exposición de la República de Platón, traducción de Miguel Cruz Hernández, Madrid: Tecnos.

- (2004). Sobre el Intelecto, edición e introducción de Andrés Martínez Lorca, Madrid: Trotta.

AviceBrón (1987). La fuente de la vida, Barcelona: Riopiedras.

Avicena (1950). Sobre Metafisica, traducción y notas de Miguel Cruz Hernández, Madrid: Revista de Occidente.

Bloch, Ernst (1964). Avicena y la izquierda aristotélica, Madrid: Ciencia Nueva.

Cruz Hernández, Miguel (1996). Historia del pensamiento en el mundo islámico, 3 vols., Madrid: Alianza.

- (1949). La Metafísica de Avicena, Universidad de Granada.

GonZÁlez Ferrín, Emilio (2006). Historia General de Al Ándalus, Almuzara.

Maimónides (2005). Guía de perplejos, Madrid: Trotta (4a edición).

Martínez LorCA, Andrés (2010). Averroes, el sabio cordobés que iluminó Europa, Córdoba, El Páramo.

- (2007). Maestros de occidente, Madrid, Trotta.

Recibido: $16 / 07 / 2011$

Aceptado: 22/08/2011 
